\title{
DIMENSIONES QUE AFECTAN LA CALIDAD DE LA DEMOCRACIA A NIVEL SUBNACIONAL EN COLOMBIA *
}

\section{Dimensions Affecting Democracy Quality at Colombia Subnational Level}

Milton Andrés Rojas Betancur**

Recepción: 3 de julio de 2020. Aceptación: 23 de enero de 2021.

DOI: http://dx.doi.org/10.21017/Rev.Repub.2021.v30.a97

\section{RESUMEN}

Se presenta un análisis de la calidad de la democracia a nivel subnacional en Colombia, guiado por dos preguntas: ¿Qué dimensiones de análisis tienen mayor incidencia en la calidad de la democracia en el nivel subnacional en Colombia? y ¿Acorde con su comportamiento e incidencia, qué tipología de dimensiones se pueden establecer? Dar respuesta a las preguntas impulsó construir un índice de democracia subnacional. Para describir los recorridos de los regímenes subnacionales y el comportamiento de las dimensiones de análisis se fundamenta el concepto de fluctuación de la democracia. Se identificaron dos dimensiones como aquellas que mayor afectación negativa generaron en la calidad del régimen, y se propone tres tipos de dimensiones: dimensiones estables, dimensiones que generan mayor afectación negativa y dimensiones fluctuantes.

Palabras clave: calidad democrática, democracia subnacional, instituciones políticas, fluctuación democrática.

\section{ABSTRACT}

This paper presents an analysis of the quality of democracy at the sub-national level in Colombia, guided by two questions: which dimensions of analysis have the greatest impact on the quality of democracy at the sub-national level in

* Este artículo se generó en la ejecución del proyecto de investigación denominado Cauca Local Economic Development (CLED) Project: A Triple Helix+ Approach towards Inclusive and Conflict-Sensitive Development in Cauca - Linking State Institutions, Entrepreneurs, and local Knowledge. El proyecto está financiado por la Universidad de Medellín y Maastricht School of Management.

** Doctor en Ciencia Humanas y Sociales, Magíster en Ciencias Políticas. Vinculado a la Facultad de Ciencias Sociales y Humanas de Universidad de Medellín. Correo electrónico:marojas@udem.edu.co; miltonrojasb@gmail.com 
Colombia? According to their behavior and incidence What type of dimensions can be established? To answer questions prompted build an index of subnational democracy. To describe the paths of sub-national regimes and the behavior of the dimensions of analysis, the concept of fluctuation of democracy is presented. Two dimensions were identified as those most negatively affected the quality of generated in the regime, and three types of dimensions are proposed: dimensionally stable, dimensions that generate greater involvement and fluctuating negative dimensions.

Key words: democratic quality, sub-national democracy, political institutions, democratic fluctuation.

\section{INTRODUCCIÓN Y PLANTEAMIENTO DEL PROBLEMA}

Las agendas de investigación sobre la democracia han generado que la comunidad académica y científica propongan herramientas metodológicas y conceptuales para analizarla empíricamente (Munck, 2010). Algunas han desembocado en la creación y posterior utilización de índices para cuantificar y valorar la calidad de la democracia a nivel nacional. Estas herramientas han demostrado ser útiles y han permitido análisis de orden comparativo sincrónicos de regímenes políticos democráticos, principalmente, identificando factores y dimensiones de análisis más o menos estables y cuantificables que facilitan la operacionalización conceptual, en este caso la calidad de la democracia (Tusell Callado, 2015). Adicional, los exámenes de la calidad de la democracia posibilitan ubicar y señalar déficits, ya que al identificar en las democracias factores y dimensiones de análisis, es viable establecer cuáles tienen bajo rendimiento, cosa útil para clasificar los regímenes políticos en función de cómo se desempeñan los factores y dimensiones analizados.

Sin embargo, este tipo de ejercicios y herramientas, examen de la calidad de la democracia e índices de medición, no han sido de frecuente uso para el análisis del régimen político subnacional. Aunque existen excepciones. Este artículo presenta un índice para valorar la calidad de la democracia a nivel subnacional, el cual tiene tres componentes que lo distinguen de los existentes, como se presenta a continuación: i) es diseñado para evaluar la calidad de la democracia de un régimen político, en este caso el colombiano, pues tiene en cuenta particularidades de su sistema político, tales como la descentralización administrativa y política, a diferencia de otros que lo proponen para estados federados (Belmonte, 2015; Gervasoni, 2005). Por otra parte, ii) compara unidades subnacionales, específicamente departamentos; en cambio, en su diseño metodológico los índices existentes privilegian la comparación de unidades nacionales (Morlino, 2012; 2014); además, iii) a diferencia de los que se han 
propuesto para evaluar la calidad subnacional de la democracia en Colombia, el índice que se propone no se enfoca únicamente en el factor electoral (Pino Uribe, 2018; Wills Otero et al., 2015), y acoge la corriente principal de adoptar la dimensión política de definición de la democracia como fundamento de la evaluación de la calidad democrática, diferente a propuestas que toman dimensiones sustantivas (Duque Daza, 2015).

La utilización del índice de democracia subnacional, nombre dado al que se usa en este texto, permite abordar preguntas del siguiente orden: ¿qué dimensiones de análisis tienen mayor incidencia en la calidad de la democracia en el nivel subnacional en Colombia en el periodo analizado? y ¿acorde con su comportamiento e incidencia, qué tipología de dimensiones se pueden establecer para el caso colombiano? Estas preguntas tienen como marco no discutir ni la importancia ni la existencia de las instituciones políticas democráticas, sino cuestionar que la existencia de ellas no es sinónimo de su eficiencia (Fukuyama, 2016). Presenta esto la necesidad de entender cómo se originan las instituciones políticas y cuál ha sido su evolución. Supone, además, comprender que en su proceso de adaptación a una estructura política particular estas crean sus propias características. Un régimen político democrático es como un sistema adaptativo complejo con sus propios arreglos internos que se coordinan a través de un conjunto de principios reguladores orientados hacia su mantenimiento, desarrollo y adaptación a las condiciones externas (Whitehead, 2011). Atendiendo estos presupuestos, los resultados obtenidos del examen de la calidad de la democracia subnacional en Colombia, empleado el índice mencionado, dan cuenta de que el rendimiento de las dimensiones analizadas, ubicadas en el proceso político, tiene dependencia con condicionantes del sistema político y que funcionan como restricciones, insinuando un path dependence. Lo anterior da cuenta de la importancia que los procesos históricos de formación del sistema político tienen para el rendimiento y debilidades de las instituciones políticas democráticas en la actualidad.

También se parte del supuesto de que las afectaciones negativas a las dimensiones constitutivas del régimen político no necesariamente constituyen amenazas para este. Estas afectaciones, o la mala calidad, son sinónimos de amenazas al proceso de democratización, o pérdidas sustantivas de los atributos característicos de las instituciones democráticas analizadas. No obstante, se considera que no son amenazas, pues no generan incertidumbres sobre la subsistencia del régimen político (Schedler, 2016). Esta afirmación se sustenta en que, si bien pueden existir afectaciones considerables en algunas de las dimensiones democráticas, la magnitud de la afectación no es tal como para producir un quiebre democrático o generar un régimen híbrido o la pérdida sustantiva de la cualidad latente de la institución democrática analizada.

El problema de investigación que se presenta en este artículo surge de tres reflexiones que se interrelacionan. La primera es la importancia de tener en 
contexto el Estado (la estructura política) en el que el régimen político se desarrolla, sus condicionantes institucionales como sus formas históricas de consolidación y centralización del poder. Además, en esta primera situación, es necesario tener presente que la capacidad del Estado para instaurar las instituciones democráticas no es homogénea, debido, en parte, al proceso en cómo aquel ha tomado forma. Desde este contexto, como segunda reflexión, es de dónde se debe analizar aspectos importantes del régimen político del país (el proceso político), que para el caso sería uno democrático, y el aspecto relevante sería su calidad a nivel subnacional y, la tercera, cómo condiciona la calidad a nivel subnacional el ser un Estado unitario con débil centralización del poder y a la vez descentralizado administrativamente donde lo subnacional no es homogéneo debido al proceso diferencial que han tenido en su formación. Lo presentado plantea la posibilidad de tres escenarios para el proceso político y para examinar la democracia: i) el subnacional, ii) el nacional y iii) el resultante de los vínculos institucionales entre aquellos (Gibson, 2006).

Por otra, diversos términos han sido empleados para describir los recorridos que realizan los regímenes políticos hacia, desde y en la democracia. Aunque múltiples, es posible identificar que existen cuatro términos que abarcan los recorridos básicos. El primero es el de transición hacia la democracia, que es cuando un régimen político que no era democrático empieza a hacerlo, adquiriendo las condiciones mínimas requeridas, que van acorde con el periodo en el que lo hizo, pues a mayor lejanía temporal con ese momento, menos requisitos debió satisfacer para considerar que transitó hacia la democracia (Linz, 1990; Tovar, 2009).

Habiendo pasado la frontera entre aquellos regímenes no democráticos, y estando en el espectro de aquellos que sí lo son, se puede advertir otro término: democratización, que hace alusión al recorrido que hace un régimen político que es democrático y que va afianzando o mejorando sus instituciones políticas democráticas. Este concepto está asociado al de consolidación de la democracia, que describe el establecimiento y la adaptabilidad de las estructuras, las normas y el relacionamiento entre el régimen y la sociedad civil, que permite al régimen democrático ganar autonomía y legitimidad. Por otra parte, cuando ocurre que un régimen político democrático realiza el recorrido contrario al de democratización, sin que pierda la naturaleza democrática del régimen político, se presentaría una desdemocratización, que constituye el tercer tipo de recorrido (Huntington, 1994; Tilly, 2010).

Finalmente, el cuarto recorrido sería el de quiebre democrático, que se presenta cuando un régimen político pierde las características esenciales de una democracia y se adentra en algún tipo de régimen no democrático (Diz Otero, Lois González y Novo Vázquez, 2012). 
En este artículo se propone un quinto término: fluctuación de la democracia. Este se utiliza para referir los recorridos y desplazamientos que ocurren en el interior de un régimen político, y demuestra ser útil para poder realizar análisis y descripciones de la democracia a nivel subnacional, ya que de la literatura disponible, hasta el momento, no se ha identificado un término propio que permita describir de forma adecuada cómo son las dinámicas y los movimientos de los regímenes de las diferentes unidades políticas en el interior de un régimen político, es decir, a niveles subnacionales. Este término permite hacer lo anterior por la siguiente razón: la fluctuación de la democracia se usa para hacer referencia a la discrepancia entre dos valoraciones sobre el mismo régimen político democrático, o entre dos unidades de análisis de comparación que pueden ser, por un lado, dos o más periodos de tiempo, o dos unidades territoriales a nivel subnacional, por ejemplo, departamentos. Es decir, la existencia de un desplazamiento, ascenso o descenso, en su valoración en un lapso de tiempo o en territorios comparados. La utilización de este concepto permite, por tanto, describir los resultados del análisis subnacional que se realiza de la calidad subnacional de la democracia en Colombia, ya que posibilita nombrar los rendimientos diferenciados y recorridos de la democracia en un territorio y periodo analizado.

Por otra parte, el concepto «calidad de la democracia» que se asume en este análisis alude a la valoración que se hace sobre en qué medida se cumplen las dimensiones constitutivas del concepto de democracia aplicado al caso de estudio (Rojas-Betancur, 2019; Vargas-Cullell, 2012). Se define entonces, la calidad de la democracia, como el adecuado funcionamiento de los mecanismos de elección de cargos de representación política y el rendimiento elevado de las instituciones, los valores y los principios democráticos. Esto, en un contexto donde el Estado tenga suficiente capacidad y presencia en el territorio nacional y, además, haya una cultura política democrática arraigada como una esfera de la cultura de la legalidad. Esta definición para el estudio es importante, suficiente y operativa, ya que permite iniciar de una definición de democracia, y sus parámetros de calidad, acotados a las características del régimen político colombiano ${ }^{1}$. Lo cual se logra observando el rendimiento de las instituciones políticas escogidas, que se convierte en dimensiones de análisis. En el caso se ha utilizado un concepto de democracia que parte del elaborado por Dahl $(2008 ; 2013)$ en el desarrollo de su concepto de poliarquía, que se considera que este es el punto arquidémico de los estudios empíricos contemporáneos sobre la democracia ${ }^{2}$, ya que este tipo de definiciones procedimentales, que

1 Su concreción no nace de unas exigencias de orden normativas elevadas, pues de entrada determinaría los resultados de análisis que se pretende realizar. Entre mayor sea el nivel de exigencia normativo de los parámetros, menor será el grado de calidad de la democracia que se observa.

2 Tan importe ha sido este concepto para el marco de análisis sobre la calidad de la democracia, que se ha considerado que ella es la capacidad de aprovechar el potencial 
parten de una teoría cognoscitiva que delimita a la democracia de manera tal que no solo puede diferenciarse de otras formas, sino que también permite estudiar su aparente funcionamiento a partir de medir su mayor o menor desempeño de sus instituciones constitutivas (Barberis, 2008).

El análisis de la calidad de la democracia que se realizó cubre un periodo entre los años 2007 y 2014, y su escogencia obedeció a su relativa proximidad y posibilidad efectiva de consecución de datos requeridos. Además, se constituye en un pertinente escenario de análisis, pero no en un determinante comparativo; es decir, se compara los rendimientos diferenciados de las instituciones democráticas en los departamentos de Colombia en un periodo de ocho años, sin desconocer el marco institucional determinado, esto es, los periodos presidenciales. Ambos gobiernos representan un sugestivo escenario para el análisis subnacional de la democracia, dado que en un lapso de ocho años se puede dar cuenta de un proceso político en el cual se puede examinar la calidad de la democracia y en cómo ella ha fluctuado. Además, este periodo es el último en el cual en Colombia dos periodos de gobierno han estado precedidos por mandatarios diferentes. Entre 2002 y 2010 se presentan dos periodos de gobierno, en los cuales la presidencia la ejerció Álvaro Uribe Vélez, mientras que entre 2010 y 2018, también se presentan dos periodos presidenciales en cabeza de Juan Manuel Santos.

Por otra parte, la división subnacional se hace por departamentos, lo cual permite observar las diferentes unidades territoriales, el nivel subnacional en Colombia, pues el funcionamiento de los procesos de elección popular de cargos cambia en cada territorio del interior del país y esto depende en gran medida de la capacidad y la presencia del Estado en la dación de bienes y servicios (presencia) y en la posibilidad de asegurar el monopolio de la fuerza (dominio). Igualmente, la gestión pública y la cultura de la legalidad y la democrática varía en cada departamento. Todo lo anterior es importante porque «el nivel general de democracia gozada por un ciudadano dado es una función de las características de ambos regímenes, el nacional y el subnacional, pero esto no implica que la democracia no se pueda definir y pueda ser medida independientemente en cada nivel» (Gervasoni, 2005, p. 93); esto evidencia la pertinencia de los tres escenarios para examinar la democracia: el subnacional, el nacional y el resultante entre estos.

La pregunta por la calidad de la democracia a nivel subnacional en un Estado unitario no es tan sencilla de responder como cuando se hace sobre un régimen federal. Sin embargo, la calidad democrática subnacional es un tema sen-

único que la poliarquía ofrece como régimen político (Altman, D., \& Pérez-Liñán 2002; Barreda 2012; Corbetta y Pérez-Liñán 2001). 
sible en los Estados con descentralización administrativa, como el colombiano, porque esta comprende una distribución de recursos y poderes desde el nivel central a las entidades intermedias que afecta el gobierno subnacional (Díaz L. y Rivera M., 2014), pudiendo producir opacidad sobre procesos de decisión y asignación de recursos y presupuestos (Cabrero Mendoza, 2006), e influir en la formación de procesos y relacionamientos políticos diferenciales y asimétricos entre élites del centro y la periferia (Behrend, 2011; Gibson, 2006, 2012), siendo estas asimetrías territoriales de las democracias un constante problema no resuelto en la investigación de la democracia subnacional (Pino Uribe, 2018).

Entonces, ¿por qué es importante esta relación entre capacidad estatal/administrativa, descentralización y calidad de la democracia? Porque están relacionadas de tal forma que condicionan el éxito o la calidad de la otra. Así, mala calidad de la democracia bloquearía o impediría una buena descentralización y viceversa, y generará retrocesos en el bienestar. Y los efectos esperados, o no, de diseños institucionales como la descentralización, afectan el afianzamiento de las instituciones democráticas a nivel subnacional.

\section{METODOLOGÍA}

Dar respuesta a las preguntas planteadas generó la necesidad de construir un índice y una base de datos integrada por diferentes tipos de datos: porcentajes, totales, valores agregados, tasas, etc. Para lo valoración se realizó una estandarización de los datos, que «consiste en realizar una transformación de las variables en una escala de medida común, para que todas puedan ser ingresadas posteriormente al índice» (Dirección de Bibliotecas, Archivos y Museos, 2011, p. 64). Se empleó una escala de medición común de 0-100. Valores cercanos a 100 indica mayor calidad de la democracia (democracia plena), y los cercanos a cero indica no (ausencia de) calidad del observable de la subdimensión o dimensiones medida. Se reconoce para la elaboración de este índice la influencia del TODEM usado por Morlino (2014; Morlino \& Carli, 2014a). Se acoge este influjo del TODEM, al reconocer la virtud en diferenciar dimensiones de la democracia y agruparlos en factores de calidad. Lo anterior, no solo da razón de la complejidad del concepto «democracia», diferenciando dimensiones, sino también del concepto «calidad», identificando tres factores. Este tipo de características son las que llevan a tomarlo como referente. Lo afirmado no es sinónimo, no tendría por qué entenderse, que sea una apropiación de la metodología empleada por el autor y que siga a rajatabla lo presentado por él, tanto en su forma de analizar la calidad de la democracia, como de los ítems (indicadores) que este usa. Se utilizó el índice presentado por Morlino como ejemplo para satisfacer la necesidad de las preguntas expuestas. Es una herramienta que se adecuó y se puso al servicio del problema de investigación. 
Dos fundamentales premisas fueron usadas para la escogencia de los factores, dimensiones y observables que conforman el índice: la primera es que no entendemos mejor la democracia haciendo de ella un compendio de todos los valores que compartimos (Barberis, 2008). La segunda es que se continúa reflexionando y evaluando las democracias contemporáneas en términos de los ideales y promesas de los fundadores de estos regímenes, y dado que estos eran incoherentes o impracticables, encontramos que a la democracia en la que vivimos le falta algo, y que es poca su utilidad o beneficios; pero que es necesario liberarnos de visiones maximizadoras (Bobbio, 2010; Przeworski, 2010 ) $\mathrm{o}$, por lo menos, necesitamos tener en cuenta estas situaciones al momento de proponer un índice para examinar la calidad de la democracia.

De acuerdo con el índice que se presenta, los factores de calidad agrupan dimensiones principales de la democracia, que representan las instituciones de esta, identificadas principalmente desde su aspecto político. Las subdimensiones reflejan aspectos esenciales de la dimensión, indican procedimientos, reglas y propósitos de las instituciones que pueden ser aprehensibles y cuantificables. A su vez, el observable es la unidad de análisis concreta con la cual se desea medir o cualificar la dimensión. Los factores de análisis de la calidad de la democracia subnacional escogidos son Procedimental y Contenido. En estos factores se agrupan las siguientes dimensiones: i) Estado de derecho - ED - , ii) Participación -Part -, iii) Competencia electoral -CompElec-, iv) Accountability electoral - AElect -, v) Accountability institucional - AInst - , vi) Libertades civiles - LibCiv - ; vii) Solidaridad e igualdad - SolIgual- . Las cinco primeras dimensiones pertenecen al primer factor (Procedimiento), y las restantes al segundo (Contenido). La escogencia de los factores y las dimensiones de calidad ${ }^{3}$ se hace bajo el supuesto de que estos tienen una relación recíproca, sin olvidar que la dimensión Estado de derecho es esencial. En primer lugar, porque este facilita las demandas de los ciudadanos para la rendición de cuentas, al igual que la rendición de cuentas de otras entidades. Las rendiciones de cuentas, a su vez, pueden generar un mejor sistema político y respeto a la ley. De igual forma, el Estado de derecho provee garantías para que la participación y competencia sea efectiva entre ciudadanos y grupos, lo cual podría mejorar, en consecuencia,

3 Se discute con la propuesta original TODEM elaborada por Morlino (2012, 2014), en especial en la utilización del factor Resultado, excluido del presente análisis, bajo la premisa de que los niveles de apoyo hacia la democracia en América Latina y, en particular, en Colombia, no son elevados, lo cual puede distorsionar el grado de favorabilidad hacia la democracia, más aún si se tiene en cuenta que desde 1996 hasta la 2018, entre el 25 y el 32\% de los ciudadanos les parece indiferente vivir o no en un régimen democrático según el Latinobarómetro (2020). De igual forma, discuto con Morlino, pues mezcla el ámbito de gobierno y la favorabilidad hacia este, con un adecuado funcionamiento de las instituciones democráticas. Punto crítico, pues se puede estar a favor de un gobierno sin que se sea demócrata. 
la rendición de cuentas y el monitoreo de élites mediante el voto, así como los controles institucionales a través de los pesos y contrapesos. Asimismo, promueve responsividad (responsiveness), pues posibilita que las autoridades sean más receptivas a las necesidades manifiestas de la sociedad y se tiene, entonces, mejora en la percepción de eficacia política (Morlino, 2012) (tabla 1).

Tabla 1. Índice de democracia subnacional

\begin{tabular}{|c|c|c|c|}
\hline $\begin{array}{l}\text { Factor de } \\
\text { calidad }\end{array}$ & $\begin{array}{l}\text { Dimensión de } \\
\text { calidad }\end{array}$ & Subdimensión & Observable \\
\hline \multirow{9}{*}{ Procedimental } & \multirow{5}{*}{$\begin{array}{l}\text { Estado de } \\
\text { derecho } \\
\text { (ED) }\end{array}$} & \multirow{3}{*}{$\begin{array}{l}\text { Seguridad } \\
\text { individual }^{4}\end{array}$} & $\begin{array}{l}\text { Total de víctimas del conflicto } \\
\text { armado en cada departamen- } \\
\text { to por año }\end{array}$ \\
\hline & & & $\begin{array}{l}\text { Total de actos terroristas por } \\
\text { departamento por año }\end{array}$ \\
\hline & & & $\begin{array}{l}\text { Total de secuestros por depar- } \\
\text { tamento por año }\end{array}$ \\
\hline & & Presencia judicial $^{5}$ & $\begin{array}{l}\text { Global de entrada y salida de } \\
\text { procesos judiciales por depar- } \\
\text { tamento/año }\end{array}$ \\
\hline & & $\begin{array}{l}\text { Capacidad de las } \\
\text { instituciones/Luc } \\
\text { has contra la } \\
\text { corrupción y la } \\
\text { ilegalidad }^{6}\end{array}$ & $\begin{array}{l}\text { Porcentaje de riesgos de } \\
\text { corrupción }\end{array}$ \\
\hline & $\begin{array}{l}\text { Participación } \\
\text { (Part) }\end{array}$ & $\begin{array}{l}\text { Participación en } \\
\text { procesos } \\
\text { electorales }\end{array}$ & $\begin{array}{l}\text { Total de participación en } \\
\text { procesos electorales (Total de } \\
\text { votos vs. Potencial electoral) } \\
\text { por departamento/año }\end{array}$ \\
\hline & $\begin{array}{l}\text { Competencia } \\
\text { electoral } \\
\text { (CompElec) }\end{array}$ & $\begin{array}{l}\text { Alternancia en el } \\
\text { poder }^{8}\end{array}$ & $\begin{array}{l}\text { Total de partidos presentado } \\
\text { a cargos de elección popular } \\
\text { vs. elegido (Asamblea depar- } \\
\text { tamental) }\end{array}$ \\
\hline & $\begin{array}{l}\text { Accountability } \\
\text { electoral } \\
\text { (AElect) }\end{array}$ & $\begin{array}{l}\text { Riesgos } \\
\text { electorales }\end{array}$ & $\begin{array}{l}\text { Total de municipios con } \\
\text { amenaza y riesgo electoral } \\
\text { (elecciones de congreso y } \\
\text { alcaldías) por departamen- } \\
\text { to/año electoral }\end{array}$ \\
\hline & $\begin{array}{l}\text { Accountability } \\
\text { institucional } \\
\text { (AInst) }\end{array}$ & $\begin{array}{l}\text { Evaluación de } \\
\text { desempeño por } \\
\text { órgano de control } \\
\text { independiente }^{10}\end{array}$ & $\begin{array}{l}\text { Desempeño integral de los } \\
\text { departamentos }\end{array}$ \\
\hline
\end{tabular}


Continúa Tabla 1. Índice de democracia subnacional

\begin{tabular}{|c|c|c|c|}
\hline \multirow{4}{*}{ Contenido } & \multirow{2}{*}{$\begin{array}{l}\text { Libertades } \\
\text { civiles } \\
\text { (LibCiv) }\end{array}$} & Homicidios $^{11}$ & $\begin{array}{l}\text { Total de homicidios por } \\
\text { departamento/año }\end{array}$ \\
\hline & & $\begin{array}{l}\text { Satisfacción de } \\
\text { derechos/Acceso } \\
\text { a administración } \\
\text { de justicia }{ }^{12}\end{array}$ & $\begin{array}{l}\text { Total de tutelas resueltas por } \\
\text { departamento/año }\end{array}$ \\
\hline & \multirow{2}{*}{$\begin{array}{l}\text { Solidaridad e } \\
\text { igualdad } \\
\text { (SolIgual) }\end{array}$} & $\begin{array}{l}\text { Cobertura en } \\
\text { educación }\end{array}$ & $\begin{array}{l}\text { Total de cobertura en edu- } \\
\text { cación básica por departa- } \\
\text { mento por año }\end{array}$ \\
\hline & & $\begin{array}{l}\text { Protección del } \\
\text { derecho a la salud }\end{array}$ & $\begin{array}{l}\text { Total de tutelas en salud } \\
\text { resueltas por departamento } \\
\text { por año }\end{array}$ \\
\hline \multicolumn{4}{|c|}{$\begin{array}{l}\text { En caso de que los valores dados en la estandarización sean }<0 \text { (cero) se deja en cero, en } \\
\text { caso de que dichos datos sean }>100 \text { se dejan en } 100 \text {. }\end{array}$} \\
\hline \multicolumn{4}{|c|}{ Los cálculos absolutos están realizados con la siguiente fórmula: } \\
\hline \multicolumn{4}{|c|}{$\underline{\text { ED}(\text { TVict+TATerr+TSec+PJud+PRElnst/5) }+ \text { Part+CompElec+AElect+AInst+LibCiv }}$} \\
\hline \multicolumn{4}{|c|}{$($ Hom+SatisDcho/2)+SolIgual (Edu+ProtDESC/2)7 } \\
\hline
\end{tabular}

Fuente: adaptación de Rojas-Betancur (2020).

4 La fuente utilizada fue el Registro Único de Victimas -RUV- (Unidad para las víctimas, 2018).

5 Los datos de esta subdimensión fueron tomados del Resultado de la gestión judicial en Colombia, que presenta el Consejo Superior de la Judicatura al Congreso de la República, y para el futuro, sería de quien haga sus veces respecto de estas funciones de informar al legislativo (Consejo Superior de la Judicatura, 2018).

6 Este índice está realizado por Transparencia por Colombia, capítulo nacional de la Organización No Gubernamental (ONG) Transparencia Internacional. De dichos informes se tomarán los datos para esta subdimensión (Corporación Transparencia por Colombia, 2008; 2011; 2015).

7 Los datos fueron tomados de la Registraduría Nacional del Estado Civil (Registraduría Nacional del Estado Civil de Colombia, 2018).

8 Para esta subdimensión se tuvo en cuenta solo una entidad: Asambleas Departamentales; estas son las unidades que se presentan para el análisis y la comparación. Los datos fueron tomados de la Registraduría Nacional del Estado Civil (Registraduría Nacional del Estado Civil de Colombia, 2018).

9 Los datos de esta subdimensión fueron tomados de los informes presentados por Misión de Observación Electoral -MOE- (Misión de Observación Electoral -MOE - , 2018).

10 El valor asignado fue tomado del Índice de Desempeño Integral del Departamento Nacional de Planeación -DNP- (Departamento Nacional de Planeación, 2018).

11 Los datos fueron tomados de Medicina Legal de Colombia publicados en la revista de la entidad (Acero Álvarez, 2010; De La Hoz Bohórquez, 2007; De La Hoz Bohórquez G. A., 2013; De La Hoz Bohórquez y Vélez Rodríguez, 2008; Marthe M. y Tello P., 2014; Moreno Lozada, 2012; Ricaurte Villota, 2011).

12 Los datos fueron tomados de los informes de la Defensoría del Pueblo (Defensoría del Pueblo de Colombia, 2009; 2010; 2011; 2012; 2013; 2014; 2015). 
Se destacan las siguientes ventajas metodológicas que el nivel subnacional de análisis proporciona y que justifican realizarle uno de la democracia a este nivel: i) aumentar la cantidad de observaciones, atenuando el problema de muchas variables y pocos casos. Además, ii) analizar unidades subnacionales permite mayor precisión en la codificación de los casos, buscando captar mejor las variaciones y la complejidad existentes dentro de sistema política nacional. Para finalizar, iii) la comparación subnacional posibilita advertir y valorar la naturaleza territorialmente dispar de los procesos de transformación política y social. En conjunto, estas ventajas procuran incrementar la probabilidad de lograr inferencias causales válidas, siendo una herramienta eficaz para aumentar el número de observaciones y realizar comparaciones controladas (Landman, 2011; Wills Otero et al., 2015).

Se utiliza el método comparativo puesto que es una estrategia que permite investigar instituciones u otros fenómenos macropolíticos y es un método científico disponible para estudiar procesos con multidimensionales interdimensionales e institucionales. Por otra parte, los análisis comparativos utilizan los métodos de las similitudes y las diferencias, que permiten proponer tipologías que son recursos heurísticos que permiten ubicar intereses analíticos (Della Porta y Keating, 2013; Landman, 2011).

\section{RESULTADOS Y ANÁLISIS DEL ÍNDICE SUBNACIONAL DE CALIDAD DE LA DEMOCRACIA}

Para la presentación y análisis de los datos generados por el índice de democracia subnacional, se utilizaron técnicas de estadística descriptiva y se usan diagramas de cajas de bigotes, que es una manera visual de agrupar los datos de la variable de análisis, es un resumen gráfico de los números con base en la síntesis de cinco valores estadísticos: cuartil $1-Q 1-$, cuartil $2-Q 2-$ (que es la misma mediana), cuartil 3-Q3-, límite inferior $-\mathrm{Li}-$, y límite superior - Ls - . Entre la Q1 y Q3 se contiene el 50\% de los datos centrales de la variable. Por su parte, la Q2, mediana, es una medida de localización central de los datos. Esta representación permite interpretar las variables, mostrando la distribución de los valores, proporcionando información completa sobre el grado de dispersión de los datos como el nivel de asimetría en su distribución (Moreno Trujillo, 2017). Los valores que integran cada una de estas cajas son resultantes del uso y aplicación del índice de democracia subnacional y representan, entonces, la valoración de la calidad de la dimensión analizada, para cada uno de los departamentos del país.

El análisis de cuartiles por cada una de las variables permite presentar las siguientes consideraciones: tres de las dimensiones de análisis de la calidad de 
la democracia subnacional (CdDs) tienen un comportamiento similar en los años de análisis; estas son: Estado de derecho, Libertad y Solidaridad e igualdad. Además, son las dimensiones en las cuales los rangos de distribución entre los valores son menores. Evidenciando que, en cuanto a estas dimensiones de análisis, no hay mucha fluctuación entre las unidades subnacionales. Igualmente, es de resaltar que estas son las dimensiones que presentan los valores más elevados y sus datos están estrechamente agrupados, advirtiendo homogeneidad entre los casos de análisis (figuras 1-8).

La segunda consideración es que son dos las dimensiones que tienen mayor relevancia con la afectación a la CdDs en Colombia. Esta situación se presenta porque son las que constantemente tienen los valores más bajos en los años analizados. Las dimensiones a las que se está haciendo referencia son Participación y Accountability institucional. Cada una tiene particularidades, como que los valores que se agrupan en la primera dimensión referida presentan menor rango de distribución que los que se agrupan en la segunda dimensión mencionada (figuras 1-8). Lo anterior significa que todos los casos, representados por cada valor, son similares entre sí; es decir, en lo que respecta a la dimensión Accountability institucional se presenta una mayor fluctuación en los recorridos y dinámicas que los que se presentan en la dimensión Participación.

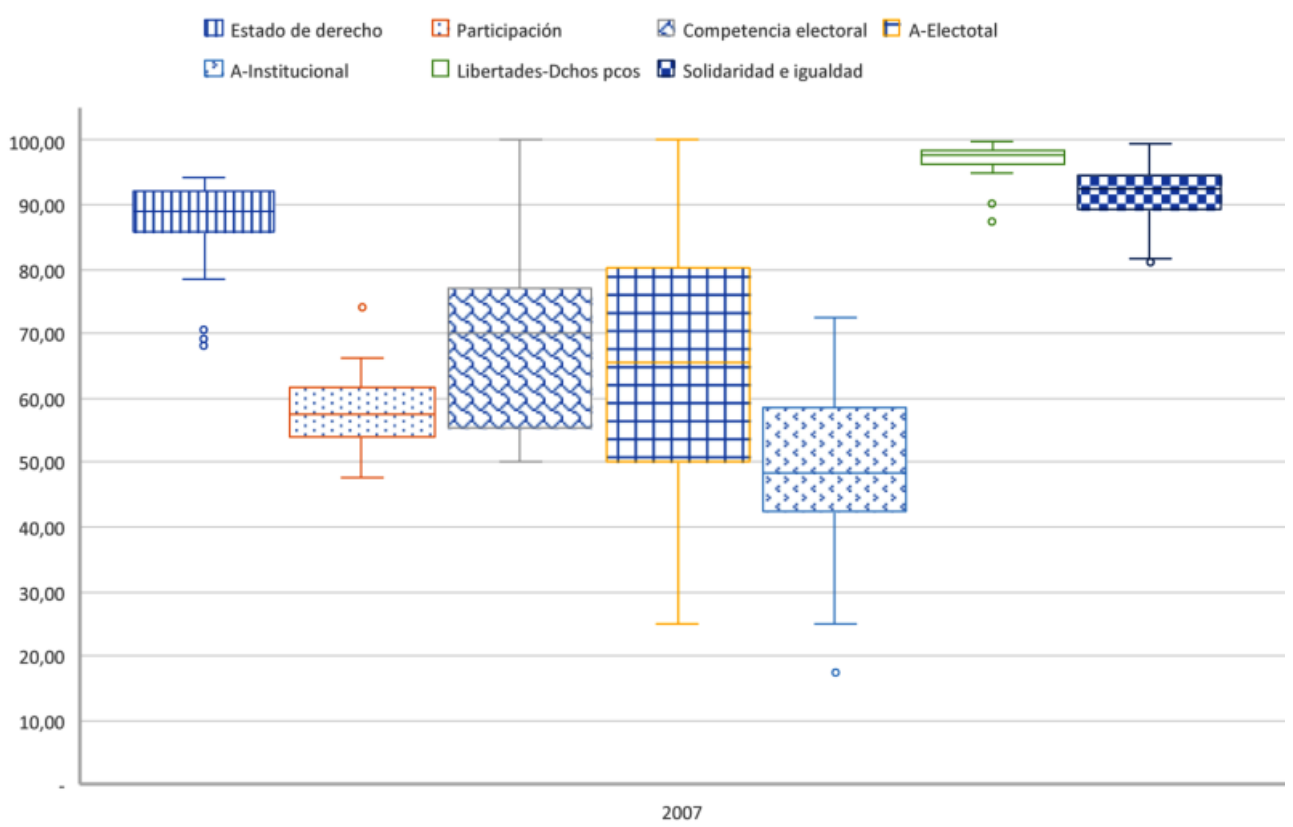

Figura 1. Comparativo de los valores de las dimensiones de análisis de la CdDs 2007. Fuente: Datos provenientes del índice de democracia subnacional. Elaboración propia. 

Ш Estado de derecho
[. Participación
$\triangle$ Competencia electoral $\mathrm{E}$ A-Electotal
3 A-Institucional
$\square$ Libertades-Dchos pcos
Solidaridad e igualdad

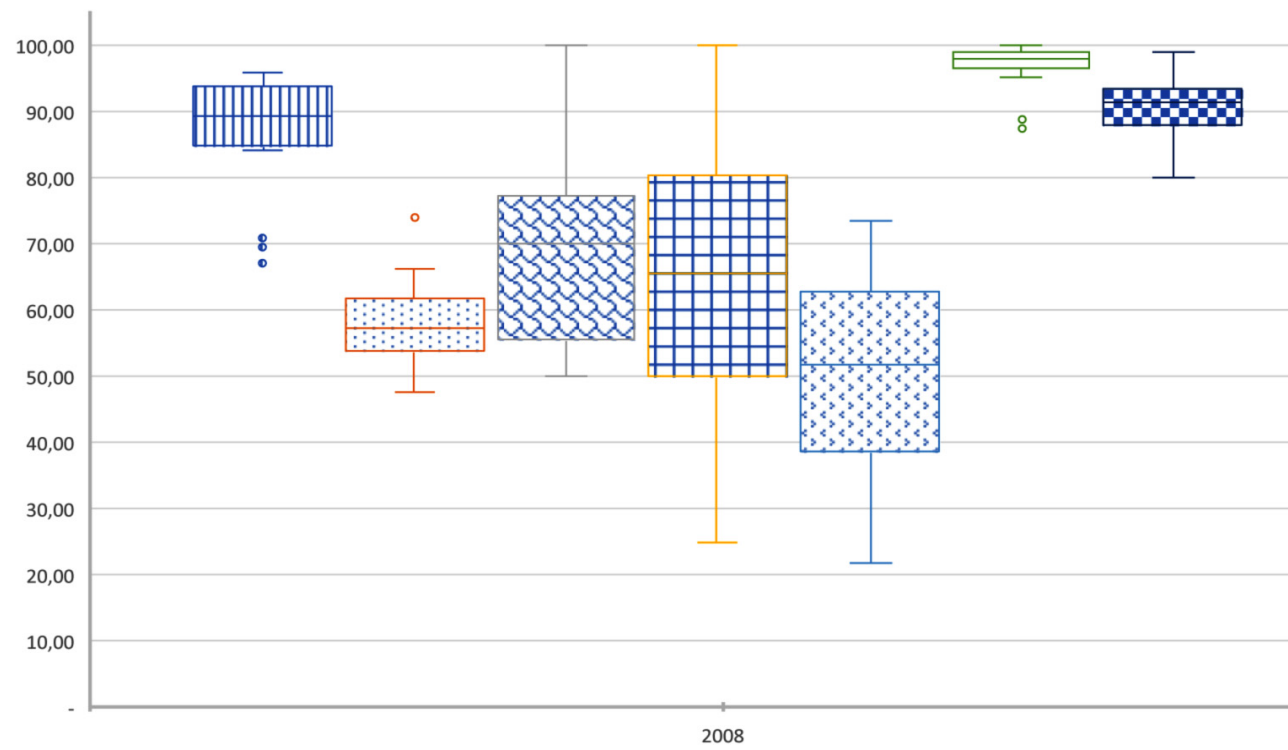

Figura 2. Comparativo de los valores de las dimensiones de análisis de la CdDs 2008. Fuente: Datos provenientes del índice de democracia subnacional. Elaboración propia.

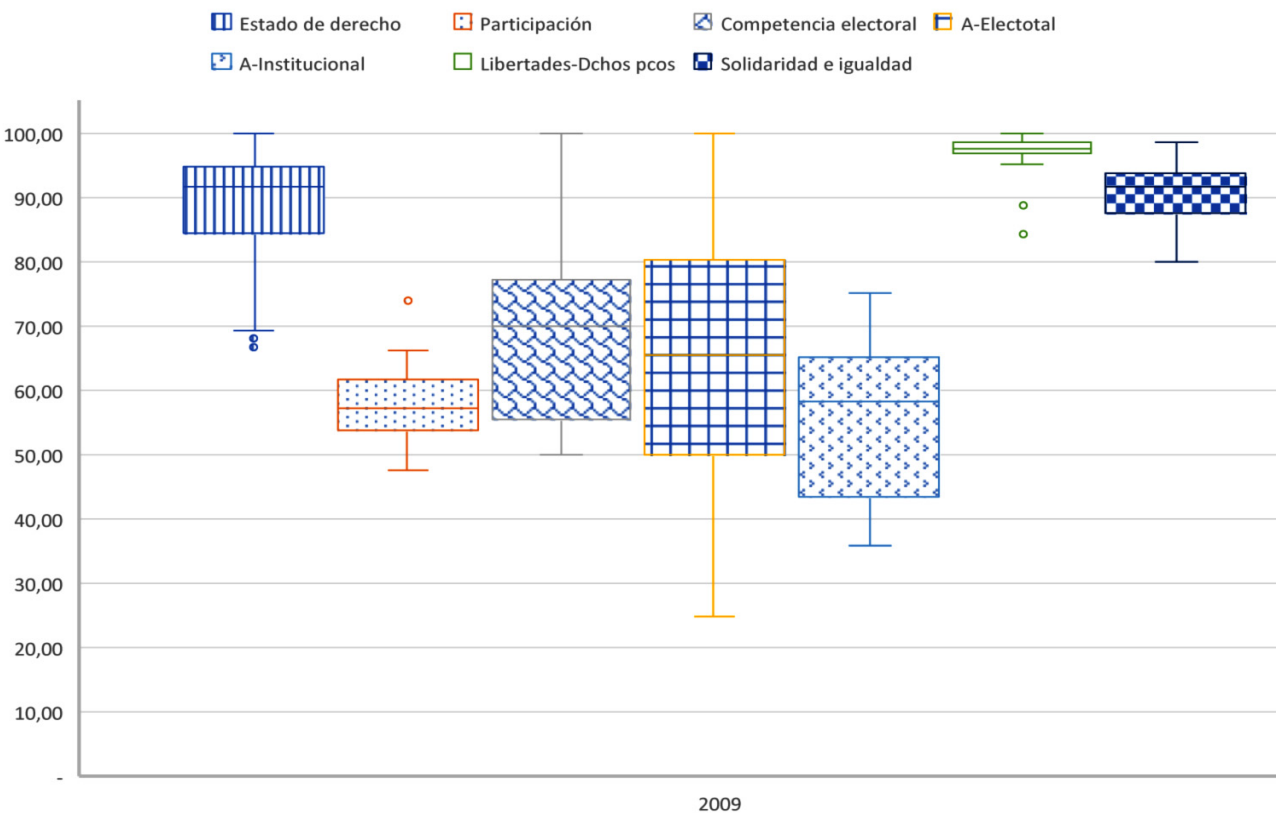

Figura 3. Comparativo de los valores de las dimensiones de análisis de la CdDs 2009. Fuente: Datos provenientes del índice de democracia subnacional. Elaboración propia. 

Ш Estado de derecho
[. Participación
$\triangle$ Competencia electoral $\square$ A-Electotal
A-Institucional
$\square$ Libertades-Dchos pcos
Solidaridad e igualdad

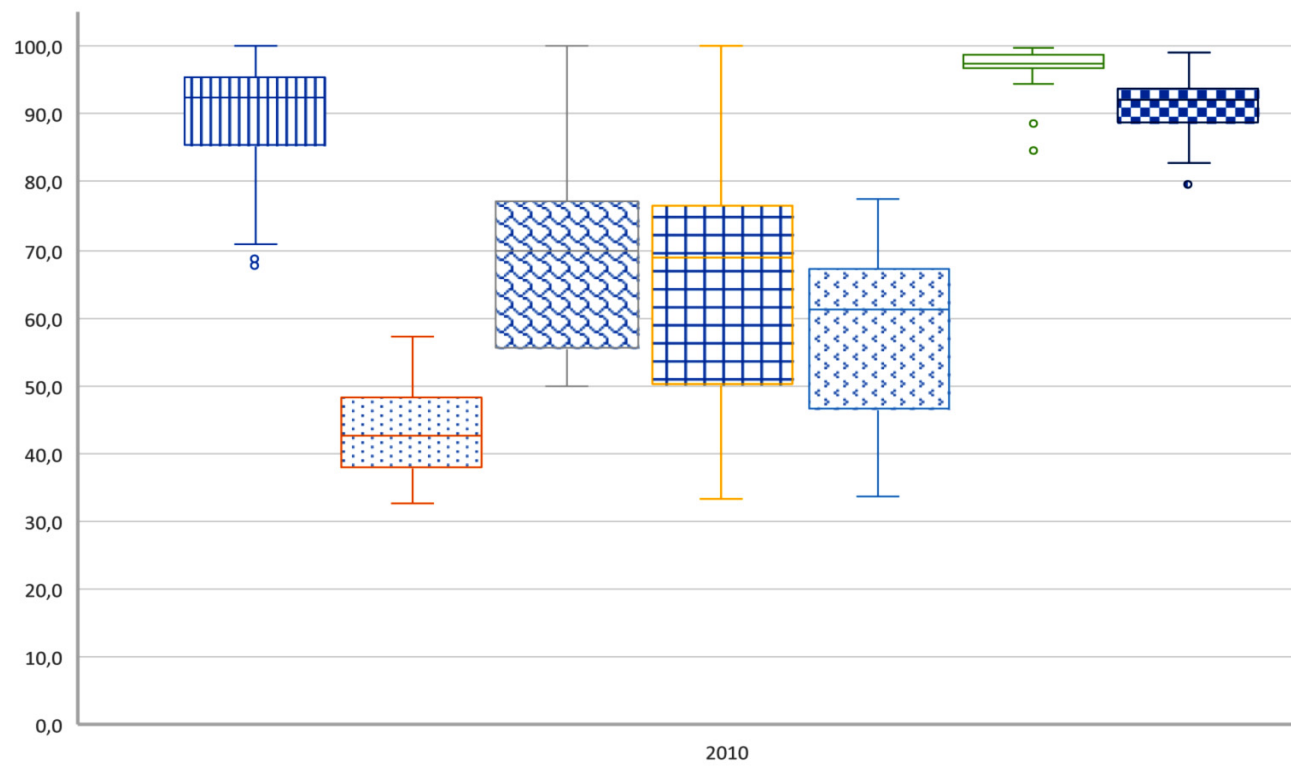

Figura 4. Comparativo de los valores de las dimensiones de análisis de la CdDs 2010. Fuente: Datos provenientes del índice de democracia subnacional. Elaboración propia.
W Estado de derecho
[.] Participación
囚 Competencia electoral $\square$ A-Electotal
3 A-Institucional
$\square$ Libertades-Dchos pcos
Solidaridad e igualdad

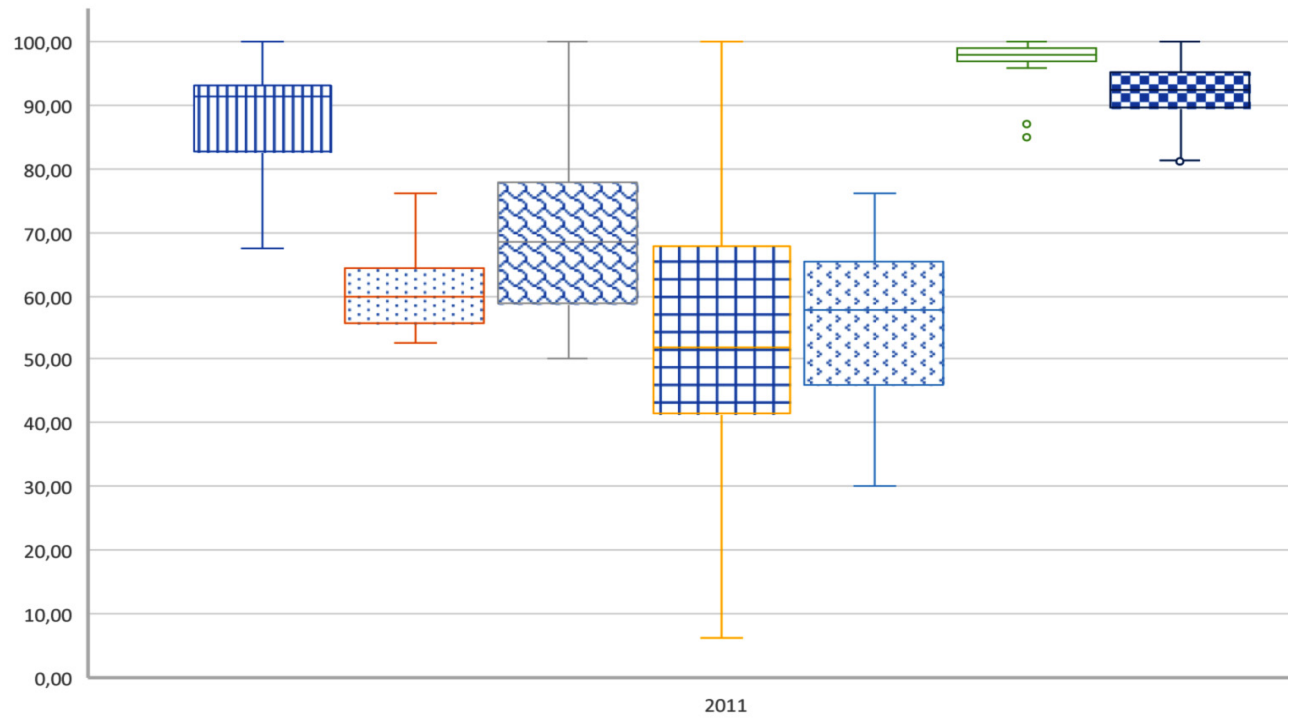

Figura 5. Comparativo de los valores de las dimensiones de análisis de la CdDs 2011. Fuente: Datos provenientes del índice de democracia subnacional. Elaboración propia. 


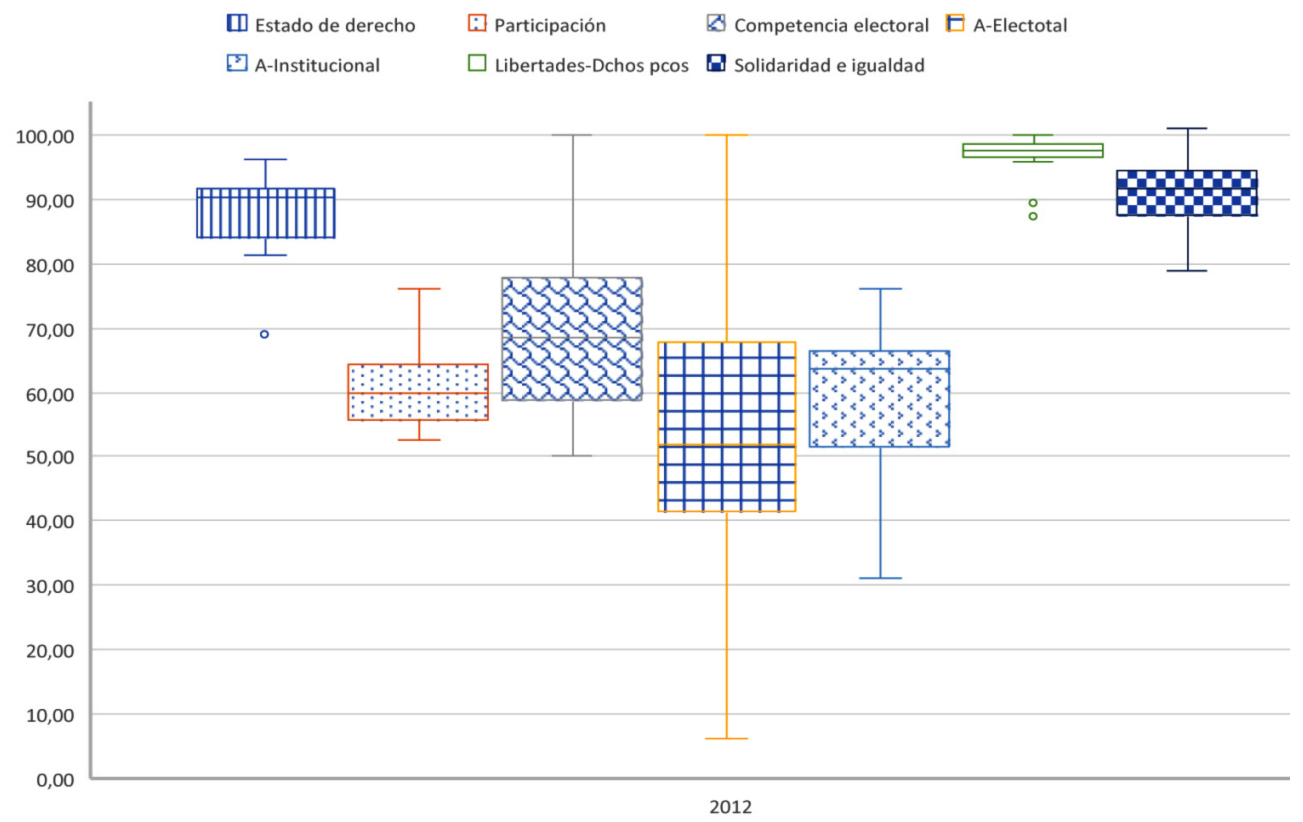

Figura 6. Comparativo de los valores de las dimensiones de análisis de la CdDs 2012. Fuente: Datos provenientes del índice de democracia subnacional. Elaboración propia.
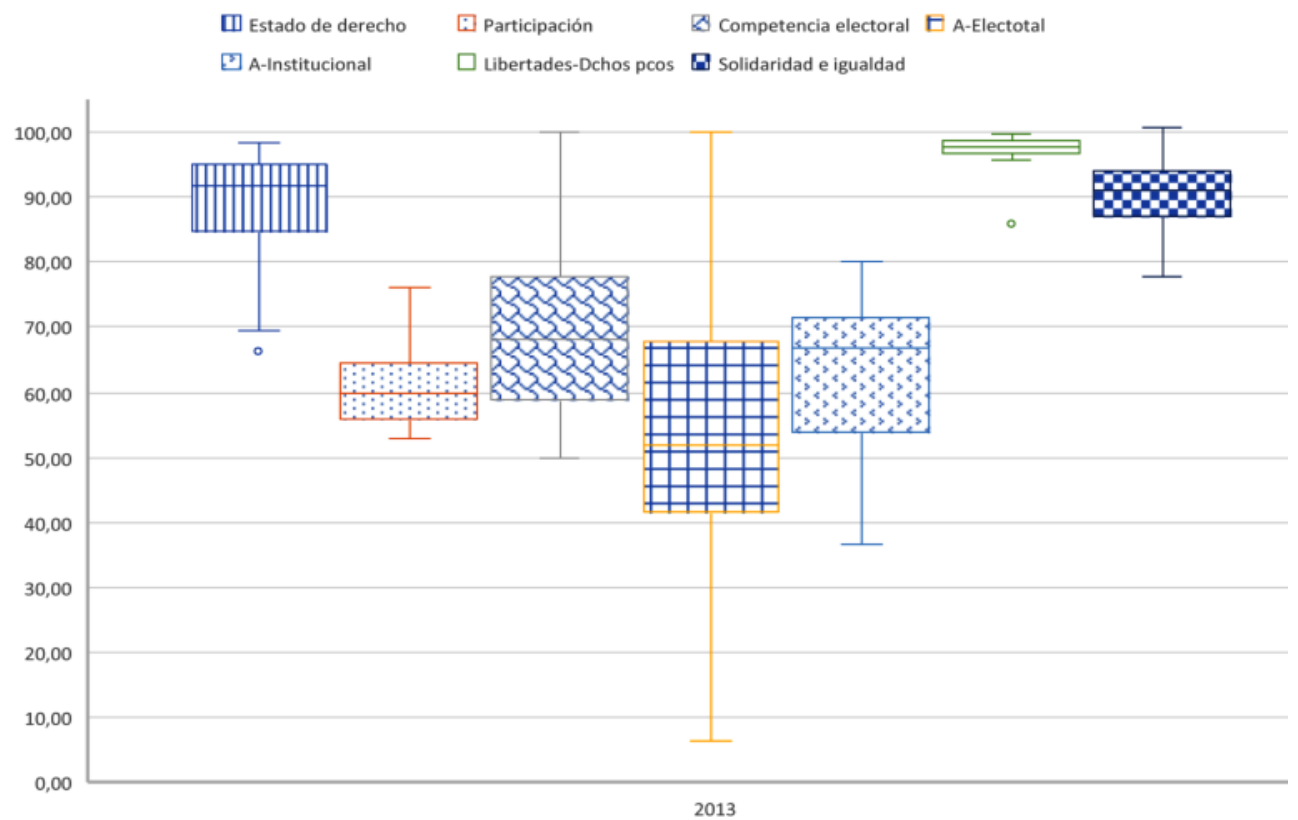

Figura 7. Comparativo de los valores de las dimensiones de análisis de la CdDs 2013. Fuente: Datos provenientes del índice de democracia subnacional. Elaboración propia. 


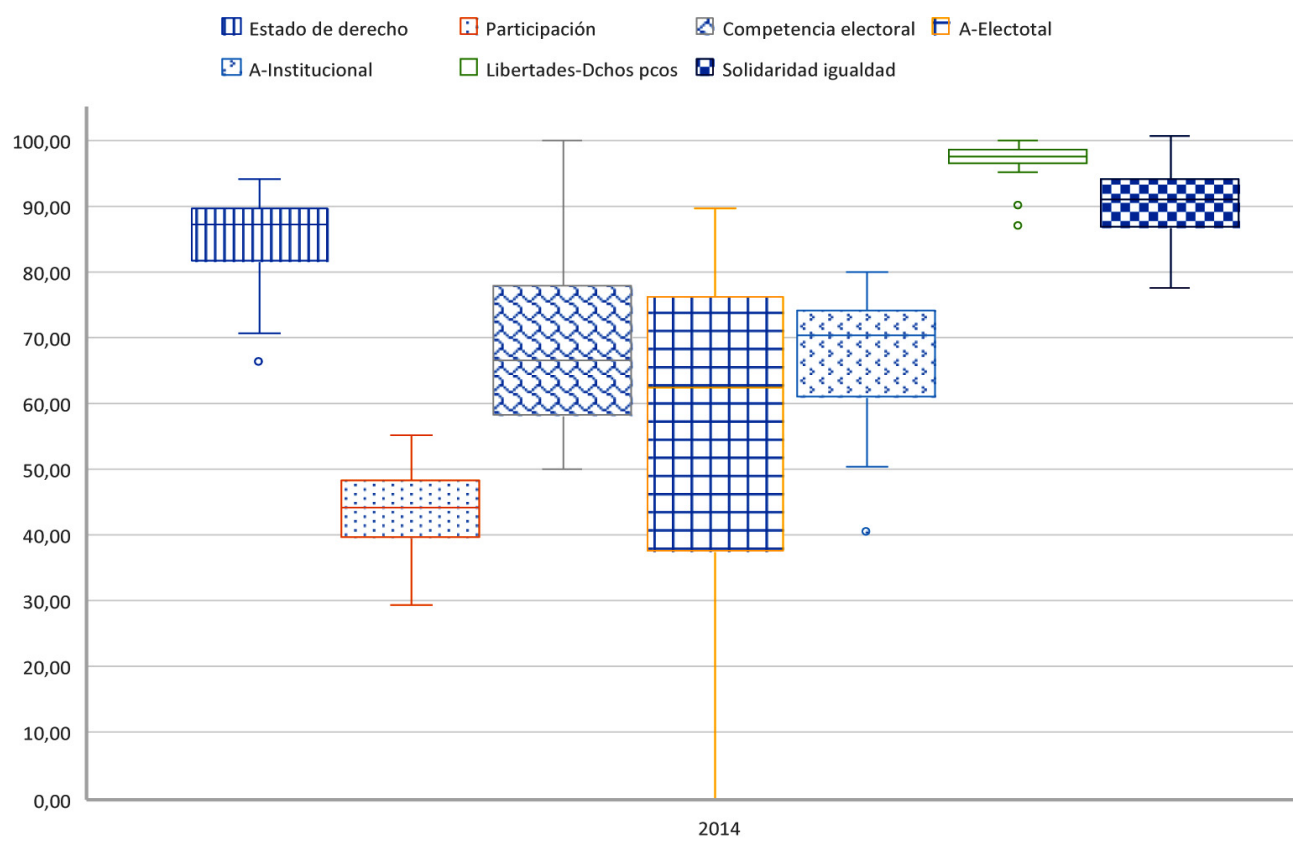

Figura 8. Comparativo de los valores de las dimensiones de análisis de la CdDs 2014. Fuente: Datos provenientes del índice de democracia subnacional. Elaboración propia.

Lo expresado genera la siguiente, y tercera, consideración: el análisis revela que hay tres dimensiones que tienen mayor fluctuación en el territorio $\mathrm{y}$, en menor medida, en el tiempo. La distribución de los valores es amplia, situación diferenciadora y característica de estas dimensiones, respecto de las enunciadoras. Las dimensiones que tienen estas características son Accountability electoral, Competencia electoral y Accountability institucional, aunque esta última ya fue mencionada en la anterior consideración. Sin embargo, hay una diferencia entre estas dimensiones que es necesario advertir. Tanto Accountability electoral como Competencia electoral tienen valores intermedios entre aquellas que tienen valores más altos (Estado de derecho, Libertades-Derechos políticos y Solidaridad e igualdad) y aquellos con los valores más bajos, entre los cuales se encuentra Accountability institucional y la dimensión Competencia electoral.

Las anteriores consideraciones permiten identificar tres tipos de dimensiones de la CdDs para Colombia. Esta tipología se estableció a partir de observar los valores, su distribución y fluctuación en el territorio y en el tiempo, y qué tanto afectan la CdDs colombiana en el periodo analizado. 
Se tiene, entonces, en primer lugar, las dimensiones estables cuyos recorridos son poco fluctuantes y sus valores son altos en todas las unidades subnacionales; es decir, corresponde con lo dicho en la primera consideración. Las dimensiones que corresponden a este tipo son Estado de derecho, Libertad y Solidaridad e Igualdad. Por otra parte, el segundo tipo de dimensiones serían las dimensiones que generan mayor afectación negativa a la democracia subnacional, que son aquellas que tienen una alta incidencia y son determinantes en la escasa calidad subnacional de la democracia por sus bajos valores y la hacen decrecer ostensiblemente. Las dimensiones que hacen parte de este tipo son las de la segunda consideración: Participación y Accountability institucional. En tercer lugar, están las dimensiones fluctuantes, que se caracterizan por ser aquellas que tienen mayores dispersiones en los valores y unas distribuciones de estos menos proporcionadas. Este tipo de variables son las que se presentaron en la tercera consideración, es decir: Accountability electoral, Competencia política y Accountability.

El examen de la calidad subnacional realizado y las consecuentes consideraciones sobre las fluctuaciones de las dimensiones analizadas evidencian que las mayores afectaciones a la CdDs que se presentan en Colombia están asociadas a dos dimensiones: Competencia electoral y Accountability institucional. La primera afectación negativa a la CdDs está ligada a la baja participación en los procesos electorales, que hace que la democracia subnacional colombiana tenga rasgos pasivos (Morlino, 2014); esto está asociado a bajos niveles en la participación electoral, pues en el periodo analizado se pueden observar participaciones tan bajas como del 32,76 \% del censo electoral (año 2010) y con máximas de 76,08\% (año 2011), aunque en general el 75\% de los departamentos tuvieron participaciones entre el 60 y $63 \%$ de sus respectivos censos electorales en los años de análisis, con las excepciones de las elecciones nacionales (Congreso y Presidencia), años 2010 y 2014, donde este 75\% estuvo entre el 48,22 y 48,38, respectivamente para cada año (Registraduría Nacional del Estado Civil de Colombia, 2018). Este rasgo se puede asociar con la baja identificación de los ciudadanos con los partidos políticos (Latinobarómetro, 2020) ${ }^{13}$ y esto, junto con la baja participación, repercute en otras dimensiones de análisis como la Competencia electoral, porque entre menor sea la participación electoral se presenta reducción en la diversidad en la representación y, en segundo lugar, hará menos complejo realizar fraudes determinantes en el resultado de las elecciones populares, y aumentará la volatilidad electoral, como expresión de la baja de identidad partidista de los votantes (Duque Daza, 2017).

13 Ante la pregunta realizada por el Latinobarómetro (2020), en el periodo de análisis, ¿Hay algún partido político hacia el cual se sienta usted más cercano que hacia el resto de los partidos?, los porcentajes de respuesta NO en Colombia fueron: 47\% (año 2010), $46 \%$ (año 2011), 73\% (año 2013). 
A pesar de que la participación en los procesos electorales es un elemento esencial de la democracia, el examen realizado evidencia que lo que más afecta negativamente la CdDs, y por ende la situación más crítica de análisis, se presenta en la dimensión Accountability institucional, sugiriendo rasgos de una democracia subnacional irresponsable, que es aquella donde, entre otras características, se presenta poca competencia entre las fuerzas políticas dominantes activas en el país y se presentan, además, débiles estructuras intermediaras, tales como movimientos sociales, sindicatos, etc. (Morlino, 2012), y el elemento de irresponsabilidad vendría dado por el bajo control que se realiza a los actores políticos determinantes del régimen político en el manejo de recursos púbicos como en el factor relacional (Duncan, 2018).

Los rasgos de esta situación pueden ser resultado del efecto de dos situaciones: i) los efectos no deseados o no esperados de la descentralización, ii) y el bajo o nulo control político que sobre los partidos políticos se realiza, vicios que a su vez repercuten en el Accountability electoral.

En primer momento, los efectos no deseados o no esperados de la descentralización tienen contraste con algunas características del sistema político colombiano y su régimen, pues es palpable que las instituciones necesarias para la democracia (división e independencia de poderes, frecuencia y alternancia en el poder, partidos políticos diferenciables y constantes, ausencia de dictaduras o autoritarismos) se presentan en Colombia desde la conformación del Estado; y que en términos de comparación regional, aquellas han tenido un funcionamiento adecuado. Sin embargo, ellas se combinan e incluso rivalizan con otras instituciones informales que son promovidas por diferentes actores, ilegales principalmente, que también compiten con el Estado por primar sobre él o procuran articularse con actores del sistema político para beneficio propio.

Quizás la consecuencia no intencionada de la descentralización administrativa más palpable es que las diferentes unidades administrativas subnacionales generaron núcleos territoriales con procesos políticos con características y dinámicas propias (Behrend, 2011), moldeando sus propias instituciones políticas, bajo una lógica de propios óptimos (Gutiérrez, 2014), o lo que el ya citado Whitehead (2011) nombra como acuerdos internos. Para Colombia, la descentralización produjo diversos efectos secundarios, como que los actores armados ilegales, y otros dedicados a economías ilegales (Duncan, 2018), lograran articularse de forma creciente con el sistema político (Duque Daza, 2017; Gutiérrez Sanín, 2010; Melo, 2017; Palacios, 2012). Las regalías y rentas se configuraron en un recurso anhelado de estos actores, e incentivaron tanto el conflicto armado como la cooptación y transformación de las instituciones formales del Estado (Garay Salamanca y Salcedo-Albarán, 2010; García Villegas y Espinoza, 
2013), incluso la neutralización o anulación de los propósitos contemplados en la Constitución y la ley (García Villegas y Revelo Rebolledo, 2018). Lo referido repercute en las dinámicas del régimen democrático, en doble vía entre lo nacional y lo subnacional; en el funcionamiento de las instituciones políticas entre las unidades territoriales, y de su análisis en conjunto, y de forma comparada, se pueden dar cuenta de la CdDs. Sin embargo, es de advertir que la autonomía subnacional siempre es limitada y no equiparable a la de un Estado nacional. Es así como el régimen político nacional impone un límite a la política subnacional (Gibson, 2006), pero la política subnacional impacta sobre la política nacional y, en algunos casos, sobre el régimen político nacional. Empero, no todas las unidades subnacionales impactan sobre la política nacional ni lo hacen de la misma manera (Behrend, 2011).

Este presupuesto y los resultados obtenidos evidencian que la CdDs es el resultado de entramados, no solo institucionales, sino también relacionales. Es decir, es resultante de la combinación de instituciones, intereses y actores; y a lo que se podría sumar unas condicionantes históricas (path dependence), que para el caso colombiano es un régimen político producto de un Estado con un ejército débil, donde la incorporación de los sectores sociales se realizó por intermedio de los partidos y no tanto por mediación del Estado y no se logró un efectivo sometimiento o relación con las élites regionales (Centeno, 2014; López-Alves, 2003 ); caracterizando el régimen político colombiano como uno competitivo y restrictivo. Esta restricción se verá a lo largo de la historia política republicana de Colombia. El siglo XX estuvo caracterizado por esto (Gutiérrez, 2014), y los resultados del examen realizado a la democracia subnacional presentan evidencia de que estas restricciones en la competencia política continúan en el siglo XXI, afectando la dimensión Accountability electoral.

Por otra parte, los grandes cambios o procesos políticos que ha habido en Colombia han estado promovidos o movilizados por los partidos políticos, y no tanto por algún tipo de acción colectiva ejercida por un movimiento social. Siendo, precisamente, sobre estos actores políticos no institucionalizados, movimientos sociales, sobre los cuales se ha ejercido exclusión y restricción, incluso violenta, del proceso político. No obstante, estos actores institucionalizados, partidos políticos, han compartido, y se han coadyuvado o convivido con actores que compiten con el Estado por la imposición de sus normas en las regiones (Duncan, 2018; Duque Daza, 2017; Gutiérrez, 2014; Palacios, 2012), llevando a que las élites políticas del país hayan ejercido el poder de forma despótica, pero a la vez débil (Centeno, 2014).

Así las cosas, la democracia en Colombia ha tenido unas características formales y de competencia política, especialmente si se tiene en cuenta el desarrollo del país y el contexto regional. «Los políticos colombianos conviven, desde su 
entrada al oficio, con la competencia, los pesos y contrapesos, y un núcleo de límite que hacen parte ya hace mucho tiempo de rutinas de su oficio» (Gutiérrez, 2014, pág. 115). La exclusión política no se ha producido entre los partidos, sino que la exclusión se presenta en la posibilidad de nuevos actores en el sistema político. La exclusión de estas fuerzas se hizo de forma típicamente ambigua, dejando que ellas pudieran funcionar bajo distintas modalidades. Por el contrario, la inclusión de los partidos hegemónicos en busca de coalición gubernamental era frecuente; por lo tanto, la existencia de «cogobiernos» durante el siglo XX fue recurrente (Gutiérrez, 2014).

La identificación de estas dimensiones como las que tienen mayor afectación en la CdDs tiene concordancia con la descripción hecha sobre el sistema político colombiano en el sentido de afirmar de que en Colombia se presenta un proceso político restrictivo pero estable, porque la dación de poder se da por procesos electorales consecutivos y prácticamente ininterrumpidos; sin embargo restrictivo porque hay una serie de restricciones a la entrada de nuevos actores en la competencia política (Rojas-Betancur, 2018). Lo anterior se relaciona con el legado de formación del sistema político colombiano y la competencia política que se ha desarrollado en él. En Colombia se presenta un clientelismo a cambio de compromisos electorales afectando la legitimidad del poder político, pues aumenta el aprovechamiento de recursos públicos para la satisfacción de los compromisos adquiridos (Duncan, 2018); esta característica genera obstáculos en la implementación de políticas públicas para la satisfacción de los intereses generales (Orjuela E., 2008).

Los comicios de 2007 fueron en los que el paramilitarismo tuvo mayor implicación e influencia en sus resultados electorales (Duque Daza, 2017), y resulta paradójico que estos nexos criminales se dieran con mayor intensidad en el momento exacto en el cual se estaba fortaleciendo la capacidad del Estado. En este sentido, se advierte cómo construir dominio estatal no es equivalente a cimentar democracia, y un aumento repentino en la habilidad de dominar (control del territorio y monopolio de la fuerza) puede poder en riesgo la democracia (Tilly, 2010). En este mismo periodo se desmovilizaron los paramilitares; no obstante, los vínculos de estos y la clase política continuaron, lo cual repercutió de forma definitiva en el resultado electoral de algunos departamentos, como Vaupés, Arauca, Magdalena, Casanare, Guainía, La Guajira, Córdoba y Guaviare. Particularmente, en estos tres últimos donde se comprobó por sentencia judicial que hubo actuaciones conjuntas entre paramilitares y candidatos (Duque Daza, 2017).

Sin embargo, la anterior dinámica cambió en 2010, cuando se redujeron los vínculos entre paramilitares y políticos, pero no significó que estos últimos hayan dejado de asociarse con la criminalidad, pues no desaparecieron las 
relaciones de los políticos con redes de contratistas, con quienes intercambiaron apoyos (Duncan, 2018; Duque Daza, 2017).

El segundo cambio generado por el clientelismo es que se construyen relaciones políticas a partir de lealtades personales, lo que impide que el Estado se convierta en un factor cohesionador, limitando la construcción del orden público. Se comenzó también un proceso de desinstitucionalización de los partidos, unido a un proceso de aumento relativo de autonomía de quienes ejercían el patronato en las regiones frente a la misma estructura partidista y frente a los líderes nacionales (Blanco Suárez, 2013; Rodríguez-Raga, 2001). Los anteriores puntos desembocan en un tercero, que es la afectación de la efectividad de la administración pública, pues se percibe como incapaz en la producción de bienes y servicios para satisfacer las demandas sociales.

La incidencia que tienen estas dimensiones asociadas a las funciones de los partidos políticos con la CdDs en Colombia evidencia que el sistema político tiene deficiencias para hacer cumplir las reglas democráticas, de implementar un régimen político democrático, como para generar la capacidad de dar un adecuado rendimiento a las instituciones políticas para que funcionen con estándares de calidad. Los partidos políticos son como una clase política que no tiene control, que monopoliza el proceso político, que lo restringe a la satisfacción de preferencias y beneficios específicos, que en cualquier caso no es incluyente y no ha sido claro y visible el control político ejercido sobre ellos.

\section{CONCLUSIONES}

Los ejercicios que examinan la calidad de la democracia subnacional y la fluctuación como concepto permiten evidenciar movimientos graduales de pérdida de calidad de la democracia que de ser sostenidos en el tiempo pueden advertir un proceso de desdemocratización a nivel subnacional, y en el peor de los escenarios, y a largo plazo, un quiebre democrático. Por otro lado, en caso de encontrar que estas fluctuaciones negativas se presentan en el territorio de forma significativa se pueden establecer zonas en las cuales cuestionar la existencia de los preceptos democráticos y sus instituciones, y advertir la presencia de enclaves territoriales iliberales o antidemocráticos (Behrend y Whitehead, 2017) y dependiendo de la institución afectada, caracterizar de forma debida el régimen subnacional.

Los datos presentados y el análisis realizado a estos sugieren que Colombia tiene un régimen político estable pero restrictivo, aunque con anomalías que, en principio, podrían afectar su estabilidad y luego convertirse en una amenaza; sin embargo, esto no ha ocurrido hasta el momento, lo que lleva a proponer 
que lo que sucede en Colombia es que hay un óptimo local, hay un estándar bajo de calidad, que sin embargo, ha hecho que diversas dimensiones de la democracia funcionen de forma suficiente para darle continuidad al régimen político democrático tanto nacional, como en la mayoría de las unidades subregionales (figura 9), pues los valores promedio de las dimensiones analizadas por cada departamento se mantienen estables en los años examinados.

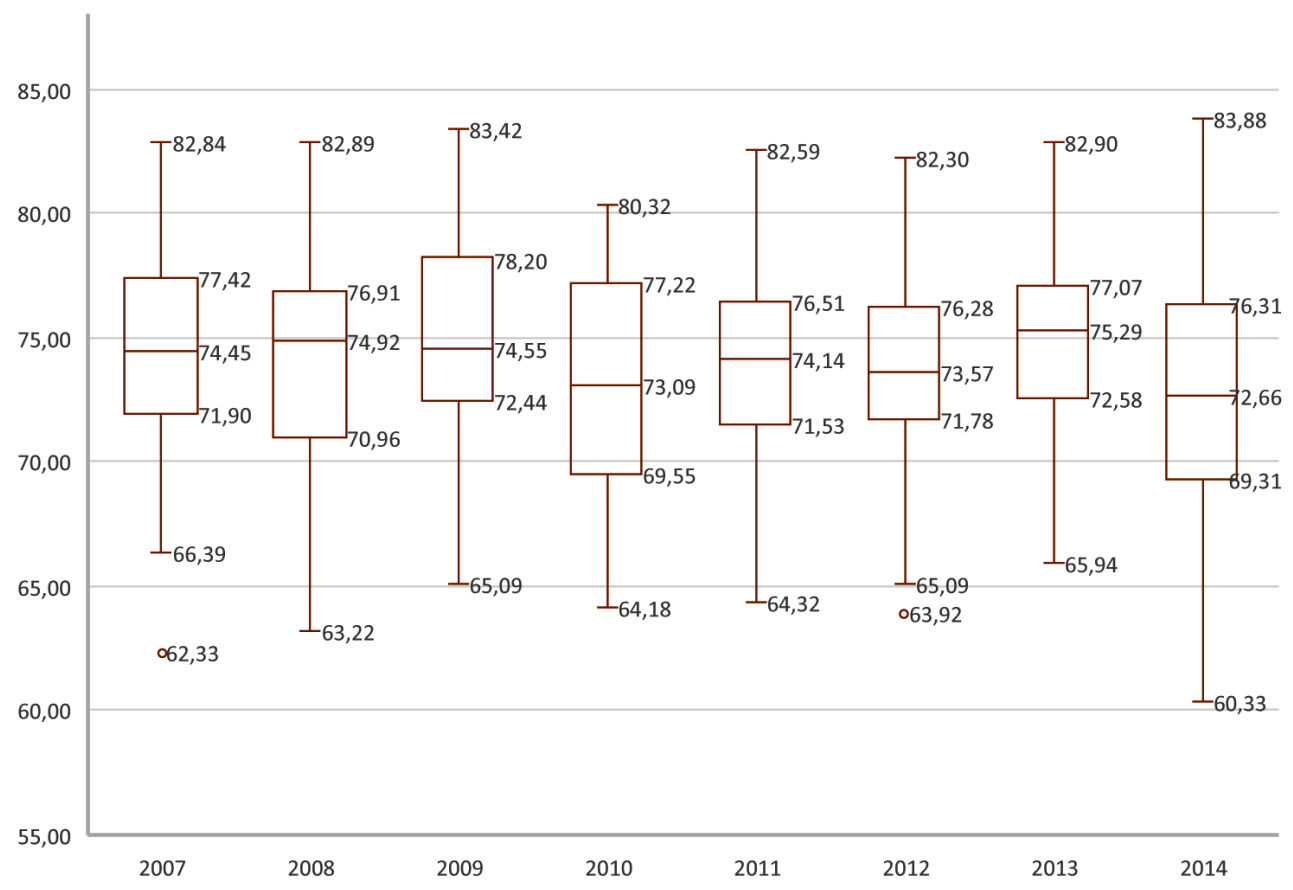

Figura 9. Valores de la calidad de la democracia subnacional entre 2007 y 2014, según el índice usado. Fuente: Datos provenientes del índice de democracia subnacional. Elaboración propia.

Se puede concluir, también, que lo que se presenta en Colombia de forma sistemática son diversas afectaciones a la democracia subnacional; es decir, hay dimensiones de análisis de la calidad de la democracia que tienen valores bajos. Sin embargo, estas afectaciones, siendo delicadas, no han puesto aún en riesgo la estabilidad del régimen político, y tampoco constituyen una amenaza a la democracia colombiana, ya que no generan incertidumbre sobre la permanencia del régimen político, pues ninguna de las dimensiones que se han identificado que afecten negativamente la CdDs, hasta el momento, son potencialmente desestabilizadores del régimen político, ya que desde hace mucho tiempo se presentan como resultado de prácticas concurrentes y carac- 
terísticas del régimen político colombiano; por lo tanto, al presentarse de larga data, no son generadores de incertidumbre sobre la sustentabilidad del régimen puesto que ya hay certeza sobre la presencia de estas afectaciones a su calidad, y los actores que compiten en la contienda electoral y política las han asumido como algo habitual, lo que sí afecta gravemente la calidad subnacional de la democracia.

El colombiano pareciera ser un régimen político obstinado en ser democrático por encima de las limitaciones de la estructura política donde se desarrolla. Es una democracia estable, restrictiva, fluctuante, con actores que la enfrentan y la corrompen, pero democracia, al fin y al cabo.

\section{BIBLIOGRAFÍA}

Acero Álvarez, A. (2010). Descripción del Comportamiento del Homicidio. Colombia, 2010. Forensis 2010 DATOS PARA LA VIDA, 18-55.

Altman, D., \& Pérez-Liñán, A. (2002). Assessing the Quality of Democracy: Freedom, Competitiveness and Participation in Eighteen Latin American Countries. Democratization, 9(2), 85-100. Disponible en: https:/ / www.tandfonline.com/doi/ abs $/ 10.1080 / 714000256$

Barberis, M. (2008). Ética para juristas. Madrid: Trotta.

Barreda, M. (2012). La calidad de las democracias latinoamericanas: medición y claves explicativas. En La calidad de la democracia: perspectiva desde América Latina, editado por Gerardo L. Munck; Sebastián Mantilla Baca, 149-179. Quito: CELAPFundación Hanns Seidel.

Behrend, J. (2011). Introducción: política subnacional y democracia. Revista SAAP, 249-260.

Behrend, J., y Whitehead, L. (2017). Prácticas iliberales y antidemocráticas a nivel subnacional. Colombia Internacional, (91), 17-43. Disponible en: https:/ / doi.org/ 10.7440/colombiaint91.2017.01

Belmonte, A. (2015). Las organizaciones de la sociedad civil en la calidad de la democracia (Tesis doctoral). Salamanca: Universidad de Salamanca.

Blanco Suárez, J. O. (2013). Estructuras clientelares y partidos políticos. Aproximaciones a la crisis y transformación de los sistemas de partidos en Colombia y Venezuela. Revista de Relaciones Internacionales, Estrategia y seguridad, 8 (1): 207-231. Disponible en: https:// doi.org/10.18359/ries.75 
Bobbio, N. (2010). El futuro de la democracia. México: Fondo de Cultura Económica.

Cabrero Mendoza, E. (2006). Los retos institucionales de la descentralización fiscal en América Latina. Revista del CLAD Reforma y Democracia, 34: 1-19. Disponible en: http://siare.clad.org/revistas/0053901.pdf

Cejudo, G., Sánchez, G., y Zabaleta, D. (2009). El (casi inexistente) debate conceptual sobre la calidad del gobierno. Política y gobierno, 16(1): 115-156. Disponible en: http://www.politicaygobierno.cide.edu/index.php/pyg/article/view/661/560

Centeno, M. Á. (2014). Sangre y deuda: ciudades, Estado y construcción de nación en América Latina. Bogotá: Editorial Universidad Nacional de Colombia.

Consejo Superior de la Judicatura. (2018). Resultado de la gestión judicial en Colombia año 2006, consultado el 24 de febrero, 2018. Disponible en: www.ramajudicial.gov.co

Corbetta, J., y Pérez-Liñán, A. (2001). Calidad de la democracia: un análisis de la trayectoria argentina. Revista Instituciones y Desarrollo, 10: 149-169.

Corporación Transparencia por Colombia. (2008). Riesgos de corrupción: fisuras en la institucionalidad departamental en Colombia, consultado el 11 de febrero, 2018, www.anticorrupcion.gov.co

Corporación Transparencia por Colombia. (2011). Índice de Transparencia Departamental Gobernaciones, consultado el 11 de febrero, 2018, www.anticorrupcion.gov.co

Corporación Transparencia por Colombia. (2015). Índice de Transparencia Departamental Gobernaciones y Contralorías, Resultados 2013-2014, consultado el 11 de febrero, 2018, www.anticorrupcion.gov.co

Dahl, R. (2008). La democracia y sus críticos. México D. F.: Paidós.

Dahl, R. (2013). La poliarquía. Madrid: Tecnos.

De La Hoz Bohórquez, G. (2007). Homicidios Colombia, 2007. Forensis 2007 DATOS PARA LA VIDA, 17-56. Disponible en: https://www.medicinalegal.gov.co/ documents/20143/49499/Homicidio.pdf

De La Hoz Bohórquez, G. A. (2013). Comportamiento del homicidio, Colombia, 2013. Forensis 2013 DATOS PARA LA VIDA, 77-125. Disponible en: https://www. medicinalegal.gov.co/documents/20143/49517/Homicidio.pdf

De La Hoz Bohórquez, G., y Vélez Rodríguez, M. C. (2008). Homicidios Colombia 2008. Forensis 2008 DATOS PARA LA VIDA, 21-59. Disponible en: https:// www.medicinalegal.gov.co/documents/20143/49502/Homicidios.pdf 
Defensoría del Pueblo de Colombia. (2009). La tutela y el derecho a la salud. Período 20062008.

Defensoría del Pueblo de Colombia. (2010). La tutela y el derecho a la salud 2009.

Defensoría del Pueblo de Colombia. (2011). La tutela y el derecho a la salud 2010.

Defensoría del Pueblo de Colombia. (2012). La tutela y el derecho a la salud 2011.

Defensoría del Pueblo de Colombia. (2013). La tutela y el derecho a la salud 2012.

Defensoría del Pueblo de Colombia. (2014). La tutela y los derechos a la salud y a la seguridad social 2013.

Defensoría del Pueblo de Colombia. (2015). La tutela y los derechos a la salud y a la seguridad social 2014.

Della Porta, D., \& Keating, M. (2013). ¿Cuántos enfoques hay en ciencias sociales? Introducción epistemológica. Enfoques y metodología de las ciencias sociales, editado por Donatella Della Porta y Michael Keating, 31-51. Madrid: Akal.

Departamento Nacional de Planeación. (2018). Desempeño Integral 2006-2013. Departamento Nacional de Planeación, consultado el 11 de febrero, 2018, colaboracion. dnp.gov.co/

Díaz L., G., y Rivera M., C. (2014). Capacidades subnacionales para procesos de descentralización: el caso de cuatro regiones en Chile. Revista del CLAD Reforma y Democracia 60: 161-192. Disponible en: http:/ / siare.clad.org/fulltext/0076900.pdf

Dirección de Bibliotecas, Archivos y Museos. (2011). Modelo de evaluación para identificar el aporte de las bibliotecas públicas en el desarrollo de comunidades DIBAM-CERLALC. Bogotá, D. C.: Centro Regional para el fomento del libro en América Latina y el Caribe. Disponible en: https:/ / cerlalc.org/wp-content/uploads/publicaciones / olb/PUBLICACIONES_OLB_Manual-de-aplicacion-de-un-modelo-de-evaluacionpara-identificar-el-aporte-de-las-bibliotecas-publicas-en-el-desarrollo-de-sus-comunidades-Dibam-Cerlalc_v1_01012012.pdf

Diz Otero, I., Lois González, M., y Novo Vázquez, A. (2012). Ciencia política contemporánea. Barcelona: Editorial UOC.

Duncan, G. (2018). Democracia feroz. Bogotá: Debate.

Duque Daza, J. (2015). Colombia. Democracia de baja calidad e inequidades sociales. Século XXI, Revista de Ciéncias Sociais, 5(2): 167-214. Disponible en: DOI: https:/ / doi.org/10.5902/2236672521593 
Duque Daza, J. (2017). Las urnas contaminadas. Elecciones, fraude y manipulación en la democracia colombiana 1990-2015. Medellín: La Carreta Editores.

Fukuyama, F. (2016). Los orígenes del orden político. Desde la prehistoria hasta la Revolución Francesa. Bogotá: Ariel.

Garay Salamanca, L., \& Salcedo-Albarán, E. (2010). Crimen, captura y reconfiguración cooptada del Estado: cuando la descentralización no contribuye a profundizar la democracia. En Veinticinco años de la Descentralización en Colombia, editado por Biviana. Barberena, Juan Manuel Ospina, Francisco Gutiérrez Sanín, \& Jorge Luis Garay Salamanca: 89-137. Bogotá: Fundación Konrad Adenauer.

García Villegas, M., y Espinosa R., J. (2013). El derecho al Estado. Los efectos legales del apartheid institucional en Colombia. Bogotá, D. C.: Centro de Estudios de Derecho, Justicia y Sociedad, Dejusticia. Disponible en: https://www.dejusticia.org/wpcontent/uploads/2014/02/El-derecho-al-Estado-Los-efectos-legales-del-apartheidinstitucional-en-Colombia.pdf

García Villegas, M., y Revelo Rebolledo, J. (2018). La construcción del Estado local en Colombia. Análisis Político, 68-95. Disponible en: https://doi.org/10.15446/ anpol.v31n92.71098

Gervasoni, C. (2005). Poliarquía a nivel sub-nacional. Aspectos conceptuales y normativos en el contexto de las democracias federales. Colección, 16: 83-122. Disponible en: https:/ / erevistas.uca.edu.ar/index.php/COLEC/article/view/761/730

Gibson, E. L. (2006). Autoritarismo subnacional: estrategias territoriales de control político en regímenes democráticos. Desafíos, 14: 204-237. Disponible en: https:// revistas.urosario.edu.co/index.php/desafios/article/view/741/668

Gibson, E. L. (2012). Boundary Control: Subnational Authoritarianism in Federal Democracies. Cambridge: Cambridge University Press.

Gutiérrez Sanín, F. (2010). Veinticinco años de la Descentralización en Colombia. En Veinticinco años de la Descentralización en Colombia, editado por Biviana. Barberena, Juan Manuel Ospina, Francisco Gutiérrez Sanín, \& Jorge Luis Garay Salamanca: 11-51. Bogotá: Fundación Konrad Adenauer.

Gutiérrez, F. (2014). El orangután con sacovelo. Cien años de democracia y represión en Colombia (1910-2010). Bogotá: IEPRI: Debate.

Huntington, S. (1994). La tercera ola. La democratización a finales del siglo XX. Buenos Aires: Paidós.

Landman, T. (2011). Política comparada. Una introducción a su objeto y métodos de investigación. Madrid: Alianza Editorial. 
Latinobarómetro. Análisis Online. Obtenido de Hay algún partido político hacia el cual se siente más cercano, consultado el 1 de marzo, (2020), www.latino barometro.org/latOnline.jsp

Linz, J. (1990). Transiciones a la democracia. REIS, 51: 7-33. Disponible en: http:// www.reis.cis.es/REIS/PDF/REIS_051_03.pdf

López-Alves, F. (2003). La formación del estado y la democracia en América Latina 18301910. Bogotá: Editorial Norma.

Marthe M., A., \& Tello P., J. (2014). Comportamiento del homicidio. Colombia, 2014. Forensis 2014 DATOS PARA LA VIDA, 91-130. Disponible en: https://www. medicinalegal.gov.co/documents/20143/49520/Forensis+2014+Datos+ para+la+vida.pdf

Melo, J. (2017). Historia mínima de Colombia. México D. F.: El Colegio de México: Turner.

Misión de Observación Electoral -MOE - . (2018). Datos Electorales, consultado el 12 de marzo, 2018, www.datoselectorales.org

Moreno Lozada, S. (2012). Lesiones de causa externa, Colombia, 2012. Forensis 2012 DATOS PARA LA VIDA, 11-106. Disponible en: https://www.medicinalegal. gov.co/documents/20143/49514/Homicidio.pdf

Moreno Trujillo, J. (2017). Estadística para ciencias sociales. Bogotá: Universidad Externado de Colombia.

Morlino, L. (2012). Observando las diferentes calidades de la democracia. Revista Mexicana de Análisis Políticos y Administración Pública, I(I): 9-48. Disponible en: http:/ /www.remap.ugto.mx/index.php/remap/article/view/2/2

Morlino, L. (2014). La calidad de las democracias en América Latina. Estocolmo: IDEA Internacional. Disponible en: https://www.idea.int/sites/default/files/ publications/la-calidad-de-las-democracias-en-america-latina.pdf

Morlino, L., \& Carli, L. (2014a). How to Assess a Democracy. What Alternatives? Moscow: Higher School of Economics Publ. House. Disponible en: https://www.hse.ru/ data/2014/03/25/1318948855/Morlino,\%20Carli-text.pdf

Munck, G. (2010). Los orígenes y la durabilidad de la democracia en América Latina: Avances y retos de una agenda de investigación. Revista de ciencia política, 30(3): 573-597. Disponible en: https:/ / scielo.conicyt.cl/pdf/revcipol/v30n3/art01.pdf

Orjuela E., L. J. (2008). Tensión entre tradición y modernidad (1904-1945). En J. F. Ocampo T., Historia de las ideas políticas en Colombia (pág. 421). Bogotá: Taurus. 
Palacios, M. (2012). Violencia pública en Colombia, 1958-2010. Bogotá: Fondo de Cultura Económica.

Pino Uribe, J. (2018). Trayectorias de desarrollo: una nueva forma de conceptualizar la variación de la democracia subnacional en Colombia 1988-2015. Análisis Político, 92: 115-136. Disponible en: https://doi.org/10.15446/anpol.v31n92.71102

Przeworski, A. (2010). Quéesperar de la democracia. Limites y posibilidades del autogobierno. Buenos Aires: Siglo Veintiuno Editores.

Registraduría Nacional del Estado Civil de Colombia. (2018). Histórico de resultados Electoral, consultado el 28 de marzo, 2018, www.registraduria.gov.co

Ricaurte Villota, A. (2011). Comportamiento del Homicidio. Colombia, 2011. Forensis 2011 DATOS PARA LA VIDA, 65-100. Disponible en: https:/ / www.medicinalegal. gov.co/documents/20143/49511/Homicidio.pdf

Rodríguez-Raga, J. C. (2001). ¿Cambiar todo para que nada cambie? Representación, sistema electoral y sistema de partido en Colombia: capacidad de adaptación de las élites políticas a cambios en el entorno institucional. En Degradación o Cambio: Evolución del Sistema Político Colombiano, compilado por Francisco, 221-260. Bogotá: IEPRI Norma.

Rojas-Betancur, Milton Andrés. (2018). Caracterización del sistema político colombiano. Estructura inestable, proceso restrictivo/estable y resultados políticos bajos. Opción, 34(18): 2127-2154. Disponible en: https://produccioncientificaluz.org/ index.php/opcion/article/view/24008/24453

Rojas-Betancur, Milton Andrés. (2019). La fluctuación de la democracia en Colombia. Análisis de la calidad de la democracia subnacional en Colombia en el periodo 2007-2014, disertación doctoral, Universidad Nacional de Colombia-Sede Medellín. Disponible en: https:/ / repositorio.unal.edu.co/bitstream/handle/unal/69704/ 15272599.2019.pdf? sequence $=1 \&$ isAllowed $=y$

Rojas-Betancur, Milton Andrés. (2021). La calidad de la democracia a nivel subnacional en Colombia: análisis de su fluctuación en el periodo 2007-2014. Ciencia Política, 15(30), 23-63. https:// doi.org/10.15446/cp.v15n30.92395

Schedler, A. (2016). La política de la incertidumbre en los regímenes electorales autoritarios. México D. F.: Fondo de Cultura Económica.

Tilly, C. (2010). Democracia. Madrid: Akal.

Tovar, J. (2009). Las primeras democracias en Hispanoamérica. Política y gobierno, XVI (1): 71-113. Disponible en: http:/ / www.politicaygobierno.cide.edu/index.php/ pyg/article/view/660/559 
Tusell Callado, A. (2015). La calidad de la democracia y sus factores determinantes. Un análisis comparado de 60 países. Política y Sociedad, 52 (1): 179-204. Disponible en: https://doi.org/10.5209/rev_POSO.2015.v1.n52.45786

Unidad para las víctimas. (2018). Registro único de víctimas. Obtenido de Unidad para las víctimas: https:/ / rni.unidadvictimas.gov.co/RUV

Vargas-Cullell, J. (2012). La calidad de la democracia y el estudio comparado de la democratización. En S. Mantillla Baca, \& G. L. Munck, La calidad de la democracia: perspectiva desde América Latina. Quito: CELAP-Fundación Hanns Seidel.

Whitehead, L. (2011). Un concepto de democratización reanimado: la metáfora biológica. Revista SAAP: Sociedad Argentina de Análisis Politico, 5 (2): 401-419. Disponible en: https:/ / revista.saap.org.ar/contenido/revista-saap-v5-n2/Whitehead.pdf

Wills Otero, L., Higuera Mendieta, I., Hoyos Muñoz, C., y Uribe Mendoza, C. (2015). Calidad de la democracia electoral en Colombia. Análisis de la competencia política en los niveles nacional y subnacional, 1988-2014. Bogotá: Universidad de los Andes. Disponible en: https://wsr.registraduria.gov.co/IMG/pdf/CEDAE_-_Calidad_ democracia_electoral_Colombia.pdf 
